\title{
Dietary risk factors for colorectal cancer in Brazil: a case control study
}

\author{
Sandro Nunes Angelo ${ }^{*}$ (D), Gustavo J. Lourenço ${ }^{2}$, Daniéla O. Magro ${ }^{3}$, Helvia Nascimento ${ }^{2}$, Rogério A. Oliveira ${ }^{4}$, \\ Raquel F. Leal ${ }^{1}$, Maria de Lourdes S. Ayrizono', João J. Fagundes', Claudio S. R. Coy ${ }^{1}$ and Carmen S. P. Lima ${ }^{2}$
}

\begin{abstract}
Background: High meat intake and low consumption of vegetables, fruits and whole grains have been associated with increased risk of colorectal cancer in some relevant cohort studies conducted in distinct ethnic populations. The role of the dietary pattern on the risk of sporadic colorectal adenocarcinoma (SCA) in Brazil is unknown; therefore, it was the aim of the present study.

Methods: The dietary patterns of 169 patients with SCA and 101 controls were analysed by food frequency recall. Crude odds ratios were calculated and given within $95 \%$ confidence intervals.

Results: Patients reported higher average intakes of beef ( $32.0 \pm 1.8$ versus $23.7 \pm 1.6, P=0.0069)$, chicken $(18.1 \pm 0.9$ versus $12.2 \pm 0.8, P=0.0002)$, and pork ( $8.9 \pm 0.9$ versus $3.4 \pm 0.5, P<0.0001)$. These individuals had a $1.025,1.069$, and 1.121 -fold increased risk of SCA.

Similar consumption of fish, vegetables, fruits and whole grains was reported by patients and controls.

Conclusions: Meat consumption is greater in patients with SCA in the Brazilian population. Considering the study population - characterized by ethnic heterogeneity -, the environmental factor related to food habits may be associated with higher incidence of this disease in Brazil.
\end{abstract}

Keywords: Colorectal cancer, Dietary pattern, Lifestyle

\section{Background}

Colorectal cancer (CRC) is result of a complex interaction of variables, including external factors, such as environmental and dietary agents, or internal ones, such as somatic or hereditary disorders [1]. Some environmental or lifestyle factors, including lack of exercise and smoking, seem to act directly as carcinogens or increase somatic mutation frequency, predisposing or determining the appearance of tumour [2].

There is a clear association between dietary pattern and $\mathrm{CRC}$, but a specific carcinogen has not yet been identified to fully justify this relationship [3]. High red meat intake and low consumption of vegetables, fruits and whole grains have been associated with increased risk [4-11], and low red meat intake and high consumption of vegetables, fruits and whole grains [11-13] or

\footnotetext{
* Correspondence: sandronunesangel@uol.com.br

'Department of Digestive Surgery, Faculty of Medical Sciences, Campinas State University, Campinas, São Paulo, Brazil

Full list of author information is available at the end of the article
}

high consumption of chicken and fish [4], with decreased risk of CRC, respectively, in some, but not in all $[14,15]$ relevant cohort studies conducted in distinct ethnic populations.

Cancer is the second cause of death in the Southeast region of Brazil [16] and CRC has a high incidence and mortality in the country [17]. Conversely, the ethnic origin of the Brazilian population is highly heterogeneous, consisting of indigenous Amerindian populations and immigrants from Europe, Africa and Asia [18, 19].

Therefore, it seemed interesting to evaluate the influence of dietary patterns on the risk of sporadic colorectal adenocarcinoma (SCA) in an ethnically heterogeneous population.

\section{Methods \\ Patients and controls}

This study comprised 169 patients with histologically confirmed SCA (97 males, 72 females; 140 Caucasians, 27 Blacks, 2 Asians; median age: 60 years, range: 29-87), 
diagnosed at the Research Ethics Committee, Faculty of Medical Sciences, Campinas State University. Patients with inflammatory bowel diseases, adenomatous polyposis, or a familial history of CRC were excluded from analysis. The control group comprised 101 blood donors (77 males, 24 females; 89 Caucasians, 12 Blacks; median age: 60 years, range: 55-67) from the same hospital, with no gastrointestinal symptoms, previous cancer or a familial history of CRC. The controls were randomly selected from the local population, according to the inclusion or exclusion criteria for age, gender and ethnic origin. All procedures were performed according to institutional guidelines, and patients and controls provided written informed consent. The local (document No. 227/ 2003) and the national (document No. 1544/2003) ethical committees approved the project.

\section{Dietary intake}

Dietary habits of patients and controls were evaluated using a food-frequency questionnaire developed at the United States of America [20], which was previously validated to be used in Brazilian epidemiological studies [21]. The subjects were asked about the frequency of intake of various foods for the years before SCA onset or before the interview. The frequency of meat consumption was assessed separately for beef, chicken, pork, and fish ingestion.

The classification of patients with recommended, higher or less than recommended intake of meat, fruits, whole grains, vegetables and legumes was based on the Brazilian food pyramid (Fig. 1) criteria [22]. The portion considered for different types of meat in the analysis was $120 \mathrm{~g}$.

\section{Statistical analysis}

Statistical differences between groups were tested considering the significance level at $5 \%$. To assess the strength of the association between intakes of foods and risk of colorectal cancer, crude odds ratios (ORs) were

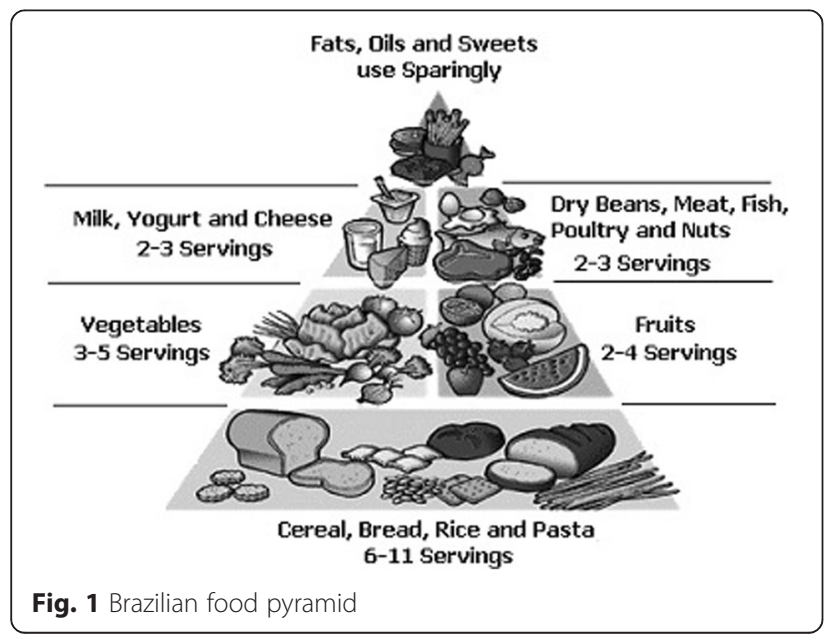

calculated with $95 \%$ confidence intervals. Patients and controls were compared according their dietary intakes in a case-control study. The multivariate logistic regression analysis was used to obtain adjusted ORs for different types of food. All analyses were performed using the SAS System 9.3 statistical package (SAS Institute Inc., Cary, NC, USA).

\section{Results}

The demographic and lifestyle characteristics of SCA patients and controls enrolled in this study were similar and are presented in Table 1.

The average monthly intakes of the various food groups and ORs for SCA are presented in Table 2. Patients reported higher intakes of beef, chicken, and pork than controls. Similar intakes of fish, vegetables, fruits and whole grains were referred by patients and controls. An increased risk of SCA was associated with higher intakes of meat. Individuals with higher intakes of beef, chicken, and pork had a 1.025, 1.069, and 1.121-fold increased risk of disease when compared with controls.

\section{Discussion}

SCA is the third most frequent malignant neoplasm in western developed countries, but it has a lower incidence in undeveloped ones [23]. In Brazil, the estimated risk considered is 13 cases $/ 100.000$ for men and 15 cases/100.000 for women. It ranks the third most

Table 1 Distribution of 169 patients with sporadic colorectal adenocarcinoma and 101 controls according to age, gender, ethic origin, smoking and alcoholism

\begin{tabular}{llll}
\hline & Patients (\%) & Controls (\%) & $P$-value \\
\hline Age (years) & & & \\
$<60$ & $81(47.9)$ & $48(47.5)$ & 0.9487 \\
$\geq 60$ & $88(52.1)$ & $53(52.5)$ & \\
Gender & & & 0.0018 \\
Male & $97(57.4)$ & $77(76.2)$ & \\
Female & $72(42.6)$ & $24(23.8)$ & 0.3435 \\
Ethnic origin & & & \\
White & $140(82.8)$ & $89(88.1)$ & \\
Black & $27(16.0)$ & $12(11.9)$ & 0.1926 \\
Asian & $02(1.2)$ & $0(0.0)$ & \\
Smoking & & & \\
Never & $78(46.2)$ & $57(56.5)$ & \\
Past & $47(27.8)$ & $26(25.7)$ & \\
Current & $44(26.0)$ & $18(17.8)$ & \\
Alcoholism & & $7(6.9)$ & \\
Never & $128(75.7)$ & $(10.9)$ & \\
Past & $21(12.5)$ & & \\
Current & $20(11.8)$ & & \\
\hline
\end{tabular}


Table 2 Distribution of 169 patients with sporadic colorectal adenocarcinoma and 101 controls according to intake of various food groups (logistic regression)

\begin{tabular}{|c|c|c|c|c|}
\hline Food consumption & Patients mean ${ }^{\mathrm{a}} \pm \mathrm{SD}$ & Controls mean $^{\mathrm{a}} \pm \mathrm{SD}$ & OR $(95 \% \mathrm{Cl})$ & $P$-value \\
\hline$\overline{\text { Beef }}$ & $32.0 \pm 1.8$ & $23.7 \pm 1.6$ & $1.025(1.007-1.044)$ & 0.0069 \\
\hline Chicken & $18.1 \pm 0.9$ & $12.2 \pm 0.8$ & 1.069 (1.032-1.108) & 0.0002 \\
\hline Pork & $8.9 \pm 0.9$ & $3.4 \pm 0.5$ & $1.121(1.061-1.185)$ & $<0.0001$ \\
\hline Fish & $5.1 \pm 0.9$ & $4.7 \pm 0.6$ & 0.999 (0.956-1.044) & 0.9732 \\
\hline Vegetables & $71.6 \pm 3.3$ & $76.8 \pm 3.8$ & $0.994(0.986-1.001)$ & 0.0995 \\
\hline Fruits & $55.3 \pm 3.5$ & $63.7 \pm 4.4$ & $0.994(0.988-1.001)$ & 0.1137 \\
\hline Whole grains & $1.2 \pm 0.4$ & $4.1 \pm 1.0$ & $0.963(0.918-1.010)$ & 0.1213 \\
\hline
\end{tabular}

${ }^{a}$ mean number of portions per month

$S D$ standard deviation, $O R$ odds ratio, $\mathrm{Cl}$ confidence interval

frequent internal cancer in men in the Southeast region of the country, whereas in the North it is the nineth [24].

The differences observed in the incidence among countries and regions suggest that environmental and diet aspects play important roles in carcinogenesis. To our knowledge, there are no studies in Brazil analysing dietary factors in SCA patients.

In this study, SCA patients had an expressive increase of meat intake, in their different types (beef, pork and chicken). This finding is similar to previous reports, which associated dietary aspects, such as high intake of red meat and saturated fat with low ingestion of fruits, vegetables, and grains containing soluble fiber and folic acid, and the increase in occurrence of SCA [9-11]. Within this context it is interesting to emphasize that studies in several countries [4-11, 25, 26] found a relation between this pattern of high consumption of meat and increased occurrence of SCA. Norat et al. performed a study of dietary patterns in ten European countries and found an increase in relative risk of SCA related to high consumption of meat and an inverse association with consumption of fish [6]. The association was also observed by Rodrigo \& Riestra and Sanz et al. in Spain [7, 27], and by Turner et al. in the United Kingdom [5].

In Japan, Lee et al. related the 'westernization' of dietary habits in that country to high intakes of meat and low fiber, and the increased incidence of SCA [8]. Conversely, Kimura et al. found no relationship between the consumption of meat and the occurrence of SCA in the Japanese population [14]. These authors observed that the high consumption of fish may be related to a lower risk of the disease. An analysis of 14 prospective studies in the U.S. and Europe, by Koushik et al., did not confirm this association with high intake of meat [15].

Comparing the intake patterns of vegetables, whole grains and fruits in patient and control groups, there was no difference, emphasizing that they were lower than those recommended in the Brazilian food pyramid (Fig. 1) criteria [22] in both groups. Voorrips et al. and
Michels et al. observed similar results without a relationship between reduced risk of SCA and vegetable and fruit consumption $[28,29]$. Similar results were found by Rodrigo \& Riestra in Spain, and by Schneider et al. in South Africa [7, 30]. Other studies [31, 32] showed that high intake of vegetables and fruits do not decrease the SCA risk; however, very low intake may be associated with SCA.

Key et al. evidenced in a review that the consumption of at least $400 \mathrm{~g} /$ day of vegetables and fruits was associated with a decreased risk of SCA in the American population [25]. Similar results were observed by Turner et al. and Yeh et al. [5, 12]. A review of over 700 works by Ryan-Harshman \& Aldoori [13] and studies developed by Turner et al., Pou et al., and Yeh et al. $[5,11$, 12] also showed that the consumption of fruits and vegetables works as a protection factor.

The findings of this study show that the intake of red meat, chicken and pork in patients with colorectal cancer is, respectively, 1.3, 1.5 and 2.6-times higher than in the control group. Considering the total meat consumption, the frequency of servings/day in patients with SCA and in the control group is, respectively, 2.54 and 1.74 . Since the amount of protein per serving considered was $120 \mathrm{~g}$, the average intake of animal protein in patients and controls was $304.8 \mathrm{~g}$ vs. $208.8 \mathrm{~g}$, respectively. There was no difference related to fish, probably because the consumption of this food in the study population was relatively low.

Some limitations of the study were not considering other risk factors, such as obesity, and not obtaining information about body mass index.

In this study, the dietary patterns of SCA patients were similar to the population from the North hemisphere and Australia [4-7, 9, 25, 26]. This can be explained by the great influence of the North American and European countries on Brazilian food habits. The characterization of dietary habits and its correlation with SCA incidence in a Brazilian population may be important in the development of education and prevention programs. 


\section{Conclusion}

Meat consumption is greater in patients with SCA in the Brazilian population. Considering the study population characterized by ethnic heterogeneity -, the environmental factor related to food habits may be associated with higher incidence of this disease in Brazil.

\section{Abbreviations}

CRC: colorectal cancer; SCA: sporadic colorectal adenocarcinoma.

\section{Competing interests}

The authors declare that they have no competing interests.

The authors declare that this article is original and it has not been published or submitted to any other journals.

\section{Authors' contributions}

SNA design, data analysis and interpretation, contribution to discussion, writing the final manuscript. GJL design, data analysis and interpretation, contribution to discussion DOM design, data analysis and interpretation, contribution to discussion. HN contribution to discussion, writing the manuscript. RAO statistical analysis and interpretation RFL data collection. MLSA data collection. JJF data collection. CSRC data analysis and interpretation, contribution to discussion, review/edit of manuscript. CSPL design, data analysis and interpretation, contribution to discussion, manuscript review/editing. All authors read and approved the final manuscript.

\section{Acknowledgments}

This work was supported by the State of São Paulo Research Foundation (Fapesp).

The authors thank Dr. Juvenal Ricardo Navarro Góes (in memorian) for their invaluable contribution to this study.

\section{Author details}

${ }^{1}$ Department of Digestive Surgery, Faculty of Medical Sciences, Campinas State University, Campinas, São Paulo, Brazil. ${ }^{2}$ Department of Internal Medicine, Faculty of Medical Sciences, Campinas State University, Campinas, São Paulo, Brazil. ${ }^{3}$ Department of Preventive and Social Medicine, Faculty of Medical Sciences, Campinas State University, Campinas, São Paulo, Brazil. ${ }^{4}$ Department of Biostatistics, Bioscience Institute, Paulista State University, Botucatu, São Paulo, Brazil.

Received: 3 November 2015 Accepted: 19 February 2016 Published online: 27 February 2016

\section{References}

1. Huxley RR, Ansary-Moghaddam A, Clifton P, Czernichow S, Parr CL, Woodward M. The impact of dietary and lifestyle risk factors on risk of colorectal cancer: a quantitative overview of the epidemiological evidence. Int J Cancer. 2009:125:171-80.

2. Lin OS. Acquired risk factors for colorectal cancer. Methods Mol Biol. 2009; 472:361-72.

3. Nystrom M, Mutanen M. Diet and epigenetics in colon cancer. World Gastroenterol. 2009;15:257-63.

4. Tiemersma EW, Kampman E, Bueno De Mesquita HB. Meat Consumption, cigarette smoking, and genetic susceptibility in the etiology of colorectal cancer: results from a Dutch prospective study. Cancer Causes Control. 2002;13:383-93.

5. Turner F, Smith G, Sachse C, Lightfoot T, Garner RC, Wolf CR, et al. Vegetable, fruit and meat consumption and potential risk modifying genes in relation to colorectal cancer. Int J Cancer. 2004;112:259-64.

6. Norat T, Bingham S, Ferrari P. Meat, fish, and colorectal cancer risk: the European Prospective Investigation into cancer and nutrition. J Natl Cancer Inst. 2005:97:906-16.

7. Rodrigo L, Riestra S. Diet and colon cancer. Rev Esp Enferm Dig. 2007;99: 183-9.

8. Lee S, Moon HY, Kwak JM. Relationship between meat and cereal consumption and colorectal cancer in Korea and Japan. J Gastroenterol Hepatol. 2008;23:138-40.
9. Gonzalez CA, Riboli E. Diet and cancer prevention: Contributions from the European Prospective Investigation into Cancer and Nutrition (EPIC) study. Eur J Cancer. 2010;46:2555-62.

10. Arafa MA, Waly MI, Jriesat S, Al Khafajei A, Sallam S. Dietary and lifestyle characteristics of colorectal cancer in Jordan: a case-control study. Asian Pac J Cancer Prev. 2011;12:1931-6.

11. Pou SA, Díaz Mdel P, Osella AR. Applying multilevel model to the relationship of dietary patterns and colorectal cancer: an ongoing casecontrol study in Córdoba, Argentina. Eur J Nutr. 2012;51:755-64.

12. Yeh CC, Hsieh LL, Tang R, Chang-Chieh CR, Sung FC. Vegetable/fruit, smoking, glutathione S-transferase polymorphisms and risk for colorectal cancer in Taiwan. World J Gastroenterol. 2005;11:1473-80.

13. Ryan-Harshman M, Aldoori W. Diet and colorectal cancer: Review of the evidence. Can Fam Physician. 2007;53:1913-20.

14. Kimura $Y$, Kono S, Toyomura K. Meat, fish and fat intake in relation to subsite-specific risk of colorectal cancer: The Fukuoka Colorectal Cancer Study. Cancer Sci. 2007:98:590-7.

15. Koushik A, Hunter DJ, Spiegelman D. Fruits, vegetables, and colon cancer risk in a pooled analysis of 14 cohort studies. J Natl Cancer Inst. 2007;99: 1471-83.

16. Duncan BB, Schmidt MI, Polanczyk CA, Mengue SS. High mortality rates among Brazilian adult populations: an international comparison. Rev Assoc Med Bras. 1992;38:138-44.

17. Das Neves FJ, Mattos IE, Koifman RJ. Colon and rectal cancer mortality in Brazilian capitals, 1980-1997. Arq Gastroenterol. 2005;42:63-70.

18. Alves-Silva J, da Silva-Santos M, Guimarães PE, Ferreira AC, Bandelt HJ, Pena SD. The ancestry of Brazilian mtDNA lineages. Am J Hum Genet. 2000;67: 444-61.

19. Carvalho-Silva DR, Santos FR, Rocha J, Pena SD. The phylogeography of Brazilian Y-chromosome lineages. Am J Hum Genet. 2001;68:281-6.

20. Segovia-Siapco G, Singh P, Haddad E, Sabate J. Relative validity of a food frequency questionnaire used to assess food intake during a dietary intervention study. Nutr Cancer. 2008;60:603-11.

21. Salvo VLMA, Gimeno SGA. Reprodutibility and validity of a food frequency questionnaire. Rev Saude Publica. 2002;36:505-12.

22. Ministério da Saúde do Brasil. Instituto Nacional de Alimentação e Nutrição. Coordenação de Orientação Alimentar. Brasília, Brasil: Manual da Pirâmide dos Alimentos; 1997

23. Parkin DM, Bray F, Ferlay J, Pisani P. Global Cancer Statistics, 2002. CA Cancer J Clin. 2005:55:74-108.

24. Boing AF, Vargas SA, Boing AC. The burden of neoplasm in Brazil: mortality and hospital morbidity from 2002 to 2004. Rev Assoc Med Bras. 2007;53: 317-22.

25. Key TJ, Schatzkin A, Willett WC, Allen NE, Spencer EA, Travis RC. Diet, nutrition and the prevention of cancer. Public Health Nutr. 2004;7:187-200.

26. English DR, Maclinnis RJ, Hodge AM, Hopper JL, Haydon AM, Giles GG. Red meat, chicken and fish consumption and risk of colorectal cancer. Cancer Epidemiol Biomarkers Prev. 2004;13:1509-14

27. Sanz MJ, Llora TS, Purón MEC, Hernández DM, Navarro AG, Rojas VD. Influence of the diet on the development of colorectal cancer in a population of Madrid. Rev Clin Esp. 2004;204:355-61.

28. Voorrips LE, Goldbohm RA, Van Poppel G, Sturmans F, Hermus RJ, Van Den Brandt PA. Vegetable and fruit consumption and risks of colon and rectal cancer in a prospective cohort study: The Netherlands Cohort Study on Diet and Cancer. Am J Epidemiol. 2000;152:1081-92.

29. Michels KB, Giovannucci E, Joshipura KJ. Prospective study of fruit, vegetable consumption and incidence of colon and rectal cancers. J Natl Cancer Inst. 2000;92:1740-52.

30. Schneider M, Norman R, Steyn N, Bradshaw D. Estimating the burden of disease attributable to low fruit and vegetable intake in South Africa in 2000. S Afr Med J. 2007:97:717-23.

31. Terry P, Hu FB, Hansen H, Wolk A. Prospective study of major dietary patterns and colorectal cancer risk in women. Am J Epidemiol. 2001;154: 1143-9.

32. McCullough ML, Robertson AS, Chao A. A prospective study of whole grains, fruits, vegetables and colon cancer risk. Cancer Causes Control. 2003; 14:959-70. 